\title{
MicroRNA-29b inhibits human vascular smooth muscle cell proliferation via targeting the TGF- $\beta /$ Smad3 signaling pathway
}

\author{
LIRONG LI, SHAOHUA REN, XUDONG HAO, ZIGANG ZHEN, LEI JI and HONGMING JI \\ Department of Neurosurgery of Shanxi Provincial People's Hospital, Taiyuan, Shanxi 030012, P.R. China
}

Received August 18, 2018; Accepted December 5, 2019

DOI: $10.3892 /$ etm.2021.9923

\begin{abstract}
Intracranial aneurysms (IAs) are bulges of blood vessels in the cerebral area. The development and progression of IAs are associated with the proliferation of vascular smooth muscle cells (VSMCs) during phenotypic modulation under environmental cues. MicroRNA-29b (miR-29b) has been studied extensively and demonstrated to reduce cell proliferation in various diseases by binding to the 3'-untranslated region (3'-UTR) of a variety of target messenger RNAs (mRNAs), thereby inhibiting their translation. The present study aimed to investigate the role of miR-29b on the proliferation of VSMCs and human umbilical artery smooth muscle cells. The results indicated that the overexpression of miR-29b reduced cell migration and proliferation. Western blotting results indicated that this effect may be attributed to the attenuation of a signaling pathway involving transforming growth factor $\beta$ (TGF- $\beta$ ) and Smad3 proteins. Luciferase assay confirmed the binding of miR-29b to TGF- $\beta 1$ and the knockdown of TGF- $\beta 1$ reduced miR-29b inhibitor-induced cell migration. The present study indicates that miR-29b downregulates the expression of TGF- $\beta 1$ by targeting the 3'-UTR of its mRNA and modulates cell migration and proliferation via the TGF- $\beta 1 / \mathrm{Smad} 3$ signaling pathway.
\end{abstract}

\section{Introduction}

Intracranial aneurysms (IAs) are pathological dilations of blood vessels in the cerebral region (1). They occur when the wall of an intracranial vessel becomes weak and forms bulges, which are susceptible to rupture. An aneurysm ruptures when the wall finally becomes too weak to resist blood pressure and this causes subarachnoid hemorrhage $(1,2)$. Surgical treatments such as ligation of the aneurysm neck are available

Correspondence to: Dr Lirong Li, Department of Neurosurgery of Shanxi Provincial People's Hospital, 29 Shuangtasi Street, Taiyuan, Shanxi 030012, P.R. China

E-mail: hjanjz9@163.com

Key words: microRNA-29b, transforming growth factor- $\beta 1$, Smad3, intracranial aneurysm, vascular smooth muscle cells, proliferation, migration for IA patients with unruptured aneurysms (3). However, all currently available surgical methods are associated with high risks of rupture, which can potentially result in catastrophic subarachnoid hemorrhage (3). To date, details of the underlying mechanism for the development and progression of IA are poorly understood. Due to the severe impacts on patients and high risks of the available surgical treatments, a less invasive medical treatment for IA is required.

Phenotypic modulation is a property of smooth muscle cells, which refers to the changes in phenotypes that occur in response to environmental cues, and includes migration, proliferation and the production of extracellular matrix (4-8). This property is profound in vascular smooth muscle cells (VSMCs) as they adapt to changes in blood pressure-induced tension and damage, and triggers the repair of damage by accelerating cell migration and proliferation (4-8). Unfortunately, phenotypic modulation also contributes to the progression of a number of vascular diseases, since cells are very susceptible to various signaling cues from the environment (9). It has been reported that phenotypic modulation of smooth muscle cells occurs in the early stage before aneurysm formation $(4,5)$. It has also been revealed that VSMCs in the cerebral aneurysm wall switch to a synthetic phenotype, in comparison with the contractile phenotype in normal cerebral arteries (10). A previous study has suggested that tumor necrosis factor- $\alpha$ plays a role in such phenotype switching, by suppressing the expression of contractile proteins and promoting the pro-inflammatory/matrix remodeling phenotype in cultured VSMCs (6). However, further investigation is required regarding the mechanisms for phenotypic modulation in IA.

MicroRNAs (miRNAs/miRs) serve an important role in gene regulation, which in turn affects the expression of certain proteins. They are short, non-coding, single-stranded RNA sequences that are 22 nucleotides in length (11-13). They act as inhibitors for mRNAs by base-pair binding to the 3'-untranslated region (UTR) of the target mRNA, which either prevents it from being translated or induces degradation. miRNA has been observed to be involved in numerous cardiac diseases, including cardiomyocyte hypertrophy, cardiac fibrosis and heart failure (11-13). Notably, it also allows the manipulation of gene expression in vivo, via the use of miRNA mimics or inhibitors (13). A previous study has suggested that miRNAs may be important in the development of IA, as 157 miRNAs were identified to be differentially expressed in tissues with aneurysm (14). Among them, miR-29b is known to be involved 
in cell proliferation and apoptosis in various diseases (15). miR-29b is a member of the miR-29 miRNA family and is encoded by the precursor stem sequence pre-miR-29b. Studies have previously demonstrated miR-29b to be a potential therapeutic agent for cardiac fibrosis $(16,17)$. Furthermore, it has also been reported that miR-29b was significantly downregulated in serum samples from patients with IA (18).

The transforming growth factor $\beta$ (TGF- $\beta$ ) family is a group of proteins that are known to regulate cell differentiation, with TGF- $\beta 1$ being the most abundant isoform (19-20). The main function of TGF- $\beta$ is to bind to its receptor protein, the TGF- $\beta$ receptor, which essentially causes the phosphorylation of Smad3 (18). Phosphorylated Smad (Smad2 and Smad3) proteins eventually form a complex that translocates into the nucleus and activates a number of transcription factors responsible for cell differentiation and migration (20). Notably, bioinformatics analysis was performed in the present study to predict potential miR-29b binding targets, where screening conducted in the present study revealed that TGF- $\beta 1$ is one of the potential targets of miR-29b. Therefore, it was speculated that miR-29b affects cell migration in IA by targeting the TGF- $\beta /$ Smad pathway. The present study aimed to investigate the role of miR-29b in the phenotypic modulation of VSMC in patients with IA and its potential underlying mechanisms, in order to facilitate the search for potential therapeutic treatments for patients with IA.

\section{Materials and methods}

Cell culture. Human umbilical artery smooth muscle cells (HUASMCs; cat. no. BH-X005; https://www.biomart.cn/ infosupply/67539695.htm?from=search_2) were purchased from Shanghai Bohu Biotechnology Co., Ltd. and cultured in Dulbecco's modified Eagle's medium (DMEM; Hyclone; GE Healthcare Life Sciences), supplemented with $10 \%$ fetal bovine serum (FBS; Gibco; Thermo Fisher Scientific, Inc.), $50 \mathrm{U} / \mathrm{ml}$ penicillin $\mathrm{G}$ and $250 \mu \mathrm{g} / \mathrm{ml}$ streptomycin (Gibco; Thermo Fisher Scientific Inc.) at $37^{\circ} \mathrm{C}$ with $5 \% \mathrm{CO}_{2}$ in an incubator. VSMCs (cat. no. DC740; https://www.biomart. cn/infosupply/48373937.htm?from=search_1) were obtained from Shanghai Zeye Biotechnology Co., Ltd. and cultured in DMEM supplemented with $10 \% \mathrm{FBS}$ at $37^{\circ} \mathrm{C}$ with $5 \% \mathrm{CO}_{2}$ in an incubator. When the cell density reached $>80 \%$, cells were washed twice with sterilized PBS. Then, $0.25 \%$ trypsin was used to dissociate cell-to-cell contacts until cells appeared detached, followed by trypsin inactivation by the addition of complete medium (DMEM supplemented with 10\% FBS). The suspended cells were gently pipetted into a centrifuge tube and collected by centrifugation $(157 \mathrm{x} \mathrm{g}, 5 \mathrm{~min})$ at room temperature. Lastly, the supernatant was removed, and cells were re-suspended in complete medium with $10 \%$ FBS for further experiments.

Cell transfection. The oligonucleotides miR-29b mimic (5'-UAGCACCAUUUGAAAUCAGUGUU-3'), mimic NC (5'-GAAUGCUGGUUUUCAUAUGGUAGA-3'), miR-29b-specific inhibitor (5'-AACACUGAUUUCAAAUG GUGCUA-3') and the corresponding negative control inhibitor (5'-CAGUACUUUUGUGUAGUACAA-3') were purchased from Sigma-Aldrich; Merck KGaA. I total, $1 \mu \mathrm{g}$
miR-29b mimic, miR-29b inhibitor or the corresponding negative control was transfected into HUASMCs and VSMCs via Lipofectamine ${ }^{\circledR} 2000$ (Thermo Fisher Scientific, Inc.). Following transfection $(24 \mathrm{~h})$ with the miR-29b mimic, treatment with TGF- $\beta 1$ at a final concentration of $1 \mu \mathrm{g} / \mathrm{ml}$ was performed. After transfection for $6 \mathrm{~h}$ at $37^{\circ} \mathrm{C}$ with $5 \% \mathrm{CO}_{2}$, cells were collected for further experimentation.

RNA interference (RNAi) and transfection. For a further knockdown experiment of TGF- $\beta 1 \mathrm{mRNA}$, a small interfering RNA (siRNA) targeting TGF-1 (si-TGF- $\beta 1$ : 5'-GCAU CUCACUCAUGUUGAUGGUCUA-3') was custom synthesized by Invitrogen (Thermo Fisher Scientific, Inc.). A non-specific scrambled siRNA (si-control: 5'-UUCUCCG AACGUGUCACGUTT-3'; MDbio, Inc.) was used as a control. Si-TGF- $\beta 1$ and si-control were each transfected into VSMCs with the Lipofectamine ${ }^{\circledR} 2000$ (Thermo Fisher Scientific, Inc.). The final siRNA concentration was $50 \mathrm{nM}$, depending on the optimal test. After transfection for $48 \mathrm{~h}$, cells were collected for the following experiments.

Reverse transcription-quantitative polymerase chain reaction (RT-qPCR). Total RNA was extracted from cells using TRIzol ${ }^{\circledR}$ reagent (Invitrogen; Thermo Fisher Scientific, Inc.) according to manufacturer's protocol. Relative expression of miR-29b in each group was measured by qPCR using a One-Step SYBR ${ }^{\circledR}$ PrimeScript ${ }^{\mathrm{TM}}$ RT-PCR kit II (Takara Bio., Inc.) according to the manufacturer's protocol 3 days after infection. The reverse transcription conditions were as follows: $37^{\circ} \mathrm{C}$ for $60 \mathrm{~min} ; 85^{\circ} \mathrm{C}$ for $5 \mathrm{~min}$ and $4^{\circ} \mathrm{C}$ for $5 \mathrm{~min}$. The qPCR reaction thermocycling conditions were as follows: Initial denaturation at $95^{\circ} \mathrm{C}$ for $1 \mathrm{~min}$, followed by 40 cycles of $95^{\circ} \mathrm{C}$ for $10 \mathrm{sec}$ and $55^{\circ} \mathrm{C}$ for $50 \mathrm{sec}$. The expression level of miR-29b was normalized by U6, whilst the level of TGF- $\beta 1$ was normalized to GAPDH using the $2^{-\Delta \Delta C q}$ method (21). The sequences for primers used for RT-qPCR were: miR-29b forward, 5'-UAGCACCAUUUGAAAUC-3' and reverse, 5'-AACGCTTCACGAATTTGCGT-3'; TGF- $\beta 1$ forward, 5 '-CAATTCCTGGCGATACCTCAG-3' and reverse, 5'-GCACAACTCCGGTGACATCAA-3'; U6 forward, 5'-GCTTCGGCAGCACATATAC-3' and reverse, 5'-AACGCTTCACGAATTTGCGT-3'; GAPDH forward, 5'-GTCAACGGATTTGGTCTGTATT-3' and reverse, 5'-AG TCTTCTGGGTGGCAGTGAT-3'.

Cell viability. A total of 9,000 cells/well was used for each set, following which MTT assay was performed using an MTT Cell Growth assay kit (Sigma-Aldrich; Merck KGaA) by following the manufacturer's protocol. DMSO was used to dissolve the purple formazan crystals. The $\mathrm{OD}_{490}$ absorbance values for the samples were measured using a plate reader.

Transwell migration assay. A Transwell Migration assay ELISA kit (Thermo Fisher Scientific, Inc.) was used to evaluate cell migration in the different groups of VSMCs and HUASMCs. The migration assay was performed by adding $200 \mu 1$ suspended cell sample $\left(4 \times 10^{8}\right.$ cells/l) to the upper chamber and $500 \mu \mathrm{l}$ DMEM with $10 \%$ FBS to the lower chamber, followed by incubation for $48 \mathrm{~h}$ at room temperature. The medium from the upper chamber was then discarded, 

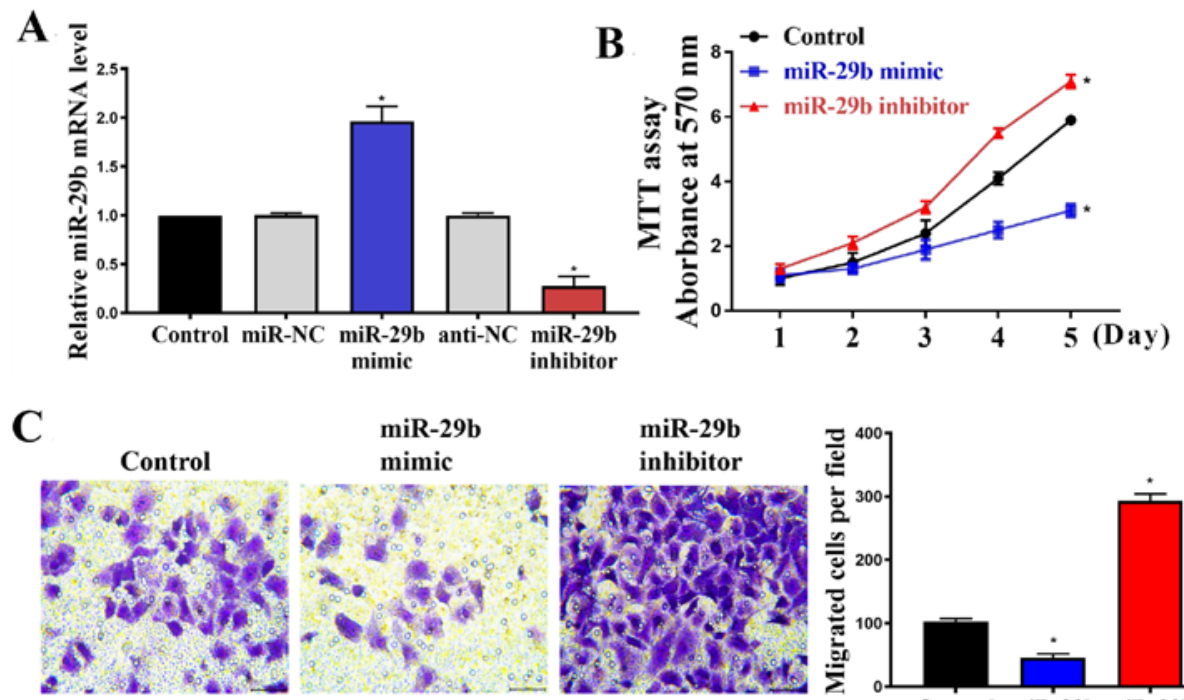

D

$\mathbf{E}$
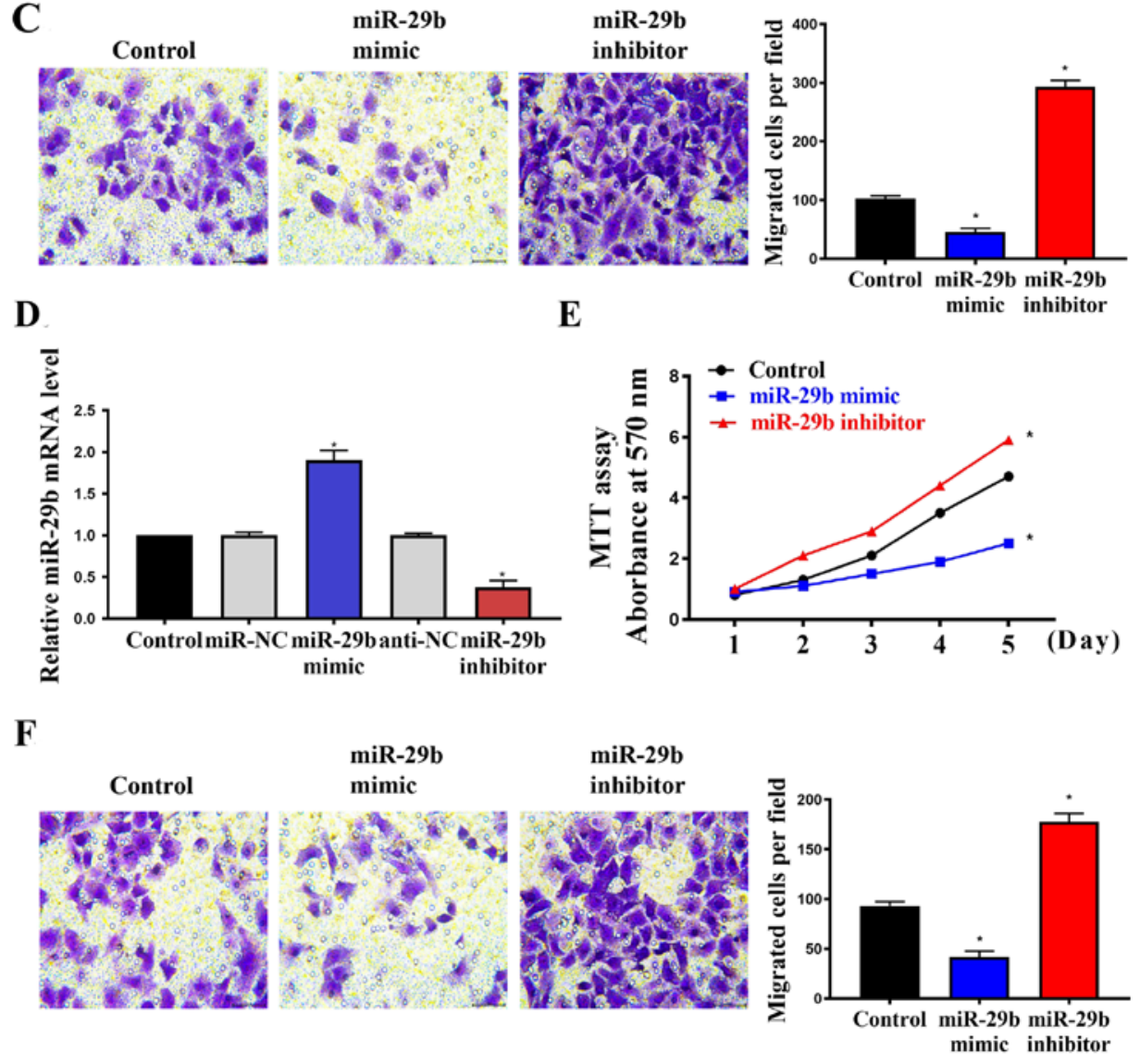

Figure 1. Effect of miR-29b on cell migration and proliferation after transfection with miR-29b mimic or inhibitor. (A) miR-29b mRNA expression levels in HUASMCs analyzed by RT-qPCR. (B) Cell growth of HUASMCs evaluated by MTT assay. (C) Cell migration of HUASMCs tested by Transwell assay. (D) miR-29b mRNA expression levels in VSMCs analyzed by RT-qPCR. (E) Cell growth of VSMCs evaluated by MTT assay. (F) Cell migration of VSMCs tested by Transwell assay. " $\mathrm{P}<0.05$ vs. control $(\mathrm{n}=6)$. HUASMCs, human umbilical artery smooth muscle cells; miR, microRNA; RT-qPCR, reverse transcription-quantitative PCR; VSMCs, vascular smooth muscle cells.

and cells on the upper surface of the membrane were cleared away using a swab. Cells on the lower surface of the membrane were then fixed for $10 \mathrm{~min}$ using $4 \%$ paraformaldehyde at room temperature and stained with $0.1 \%$ crystal violet solution at room temperature for $10 \mathrm{~min}$. The membranes were subsequently stained and viewed under a light microscope (magnification, $\mathrm{x} 20$ ) for cell counting, from images taken from five visual fields per chamber.

Luciferase reporter assay. TargetScan 7.2 (http://www. targetscan.org) used to predict potential binding targets of miR-29b. The wild-type (WT) or mutant (mut) 3'-UTR of TGF- $\beta 1$ was cloned into the pGL3 luciferase reporter vector (Shanghai GeneChem Co., Ltd.). The corresponding mutant sequence was designed to be identical to that of miR-29b to prevent sequence-specific binding. The pGL3-TGF-WT or pGL3-TGF-mut plasmid (1 $\mu \mathrm{g}$ cDNA) was co-transfected with miR-29b mimic (20 pmol RNA) into cultured VSMCs A firefly-Renilla dual luciferase assay was performed on samples $48 \mathrm{~h}$ after transfection to determine luciferase activities, using a Dual-Luciferase ${ }^{\circledR}$ Reporter assay system (Promega Corporation) following the manufacturer's protocol. Results were detected using a Synergy $2^{\mathrm{TM}}$ Microplate Reader (BioTek Instruments, Inc.).

Westernblotting.VSMCsand HUASMCs werelysed using RIPA buffer (Beyotime Institute of Biotechnology). Protein quantification was measured by performing bicinchoninic acid assay (Beyotime Institute of Biotechnology). Proteins were extracted $(30 \mu \mathrm{g})$ followed by separation using 10\% SDS-PAGE and 

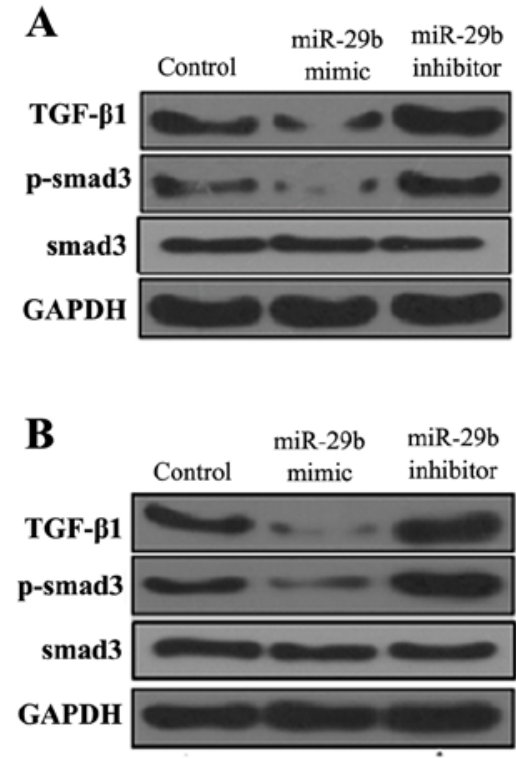
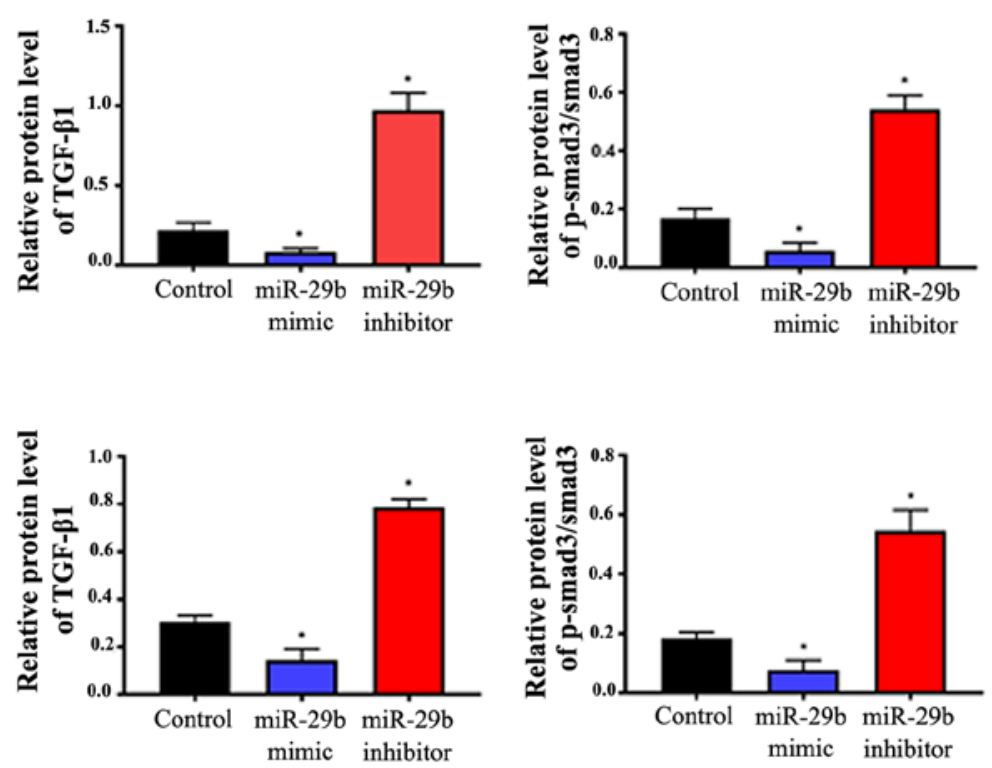

Figure 2. Overexpression of miR-29b suppresses the TGF- $\beta /$ Smad3 signaling pathway in HUASMCs and VSMCs. (A) Western blot analysis of TGF- $\beta$, Smad 3 and GAPDH in HUASMCs transfected with miR-29b mimic or miR-29b inhibitor. (B) Western blot analysis TGF- $\beta$, p-Smad3, Smad3 and GAPDH in VSMCs transfected with miR-29b mimic or miR-29b inhibitor. "P<0.05 vs. control $(\mathrm{n}=6)$. HUASMCs, human umbilical artery smooth muscle cells; miR, microRNA; p, phosphorylated; TGF- $\beta$, transforming growth factor $\beta$; VSMCs, vascular smooth muscle cells.

then transferred onto a polyvinylidene difluoride membranes. The membrane was then blocked with $5 \%$ fat-free dry milk for $2 \mathrm{~h}$ at room temperature, followed by overnight incubation with mouse anti-TGF- $\beta 1$ (cat. no. sc-130348), phosphorylated (p)-Smad3 (cat. no. sc-517575), Smad3 (cat. no. sc-101154) or GAPDH (cat. no. sc-32233) primary antibodies (1:500; Santa Cruz Biotechnology, Inc.) at $4^{\circ} \mathrm{C}$. Next, the membrane was incubated with horseradish peroxidase-conjugated goat anti-mouse IgG secondary antibody (1:6,000; cat. no. 7076; Cell Signaling Technology, Inc.) for $2 \mathrm{~h}$ at room temperature. Protein expression was then detected by enhanced chemiluminescence (ECL) using Immobilon ECL Ultra Western HRP substrate (EMD Millipore) and quantified using Quantity One software 4.6 (Bio-Rad Laboratories, Inc.).

Statistical analysis. SPSS version 16.0 statistics software (SPSS, Inc.) was used for statistical analysis throughout this study. All statistical results are presented as the mean \pm standard deviation. The data analysis between multiple groups was based on one-way analysis of variance, followed by the Student-Newman-Keuls post hoc tests (three groups) or Bonferroni post hoc tests ( $>3$ groups). Two-way ANOVA with Bonferroni post hoc test were performed when comparing the MTT results. $\mathrm{P}<0.05$ was considered to indicate a statistically significant difference.

\section{Results}

miR-29b affects cell proliferation and migration. To investigate the effect of miR-29b on cell proliferation and migration, HUASMCs and VSMCs were infected with miR-29b mimic, miR-29b inhibitor and their respective controls. The transfection efficiency was evaluated by RT-qPCR and the results confirmed that miR-29b was upregulated by miR-29b mimic and downregulated by miR-29b inhibitor significantly in both

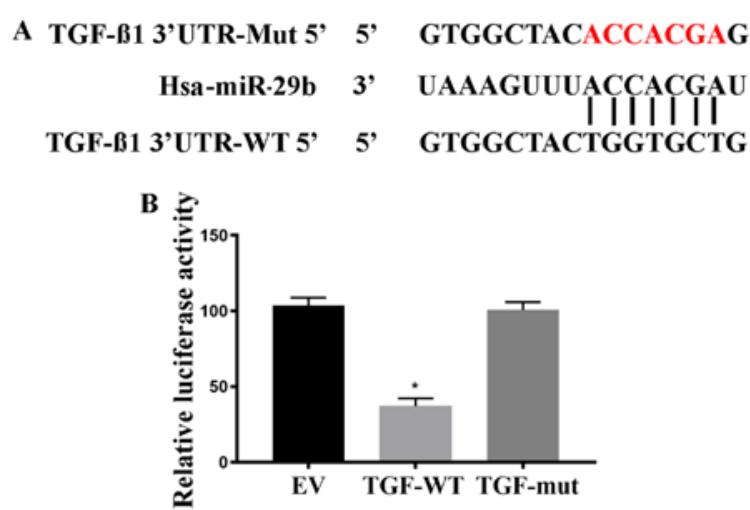

Figure 3. miR-29b inhibits the TGF- $\beta 1 / \mathrm{Smad} 3$ signaling pathway by directly targeting TGF- $\beta 1$. (A) Sequence of the binding sites of miR-29b on the 3'-UTR of TGF- $\beta 1$ predicted using TargetScan. (B) Significantly lower luciferase activity was observed with the wild-type TGF- $\beta 1$ sequence compared with the control and mutant. ${ }^{*} \mathrm{P}<0.05$ vs. $\mathrm{EV}(\mathrm{n}=6)$. EV, empty vector; miR, microRNA; mut, mutant; TGF- $\beta 1$, transforming growth factor $\beta 1$; 3 '-UTR, 3'-untranslated region; WT, wild-type.

HUASMCs (Fig. 1A; P<0.05) and VSMCs (Fig. 1D; $\mathrm{P}<0.05$ ) compared with the respective control. Regarding the role of miR-29b, MTT (Fig. 1B and E; P<0.05) and Transwell migration assays (Fig. $1 \mathrm{C}$ and $1 \mathrm{~F} ; \mathrm{P}<0.05$ ) indicated that the upregulation of miR-29b via the incorporation of miR-29b mimic significantly suppressed cell proliferation and migration compared with the control, whereas downregulation of the miRNA using the miR-29b inhibitor significantly increased these properties.

Overexpression of miR-29b suppresses the TGF- $\beta / S m a d 3$ signaling pathway in HUASMCs and VSMCs. The expression levels of TGF- $\beta 1$ and Smad3 were analyzed in all sample groups by western blotting. The results indicated that overex- 
A

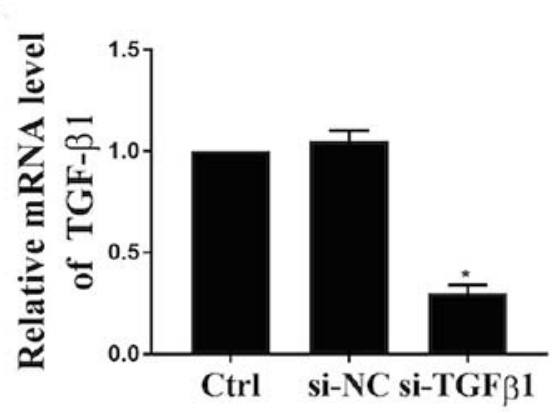

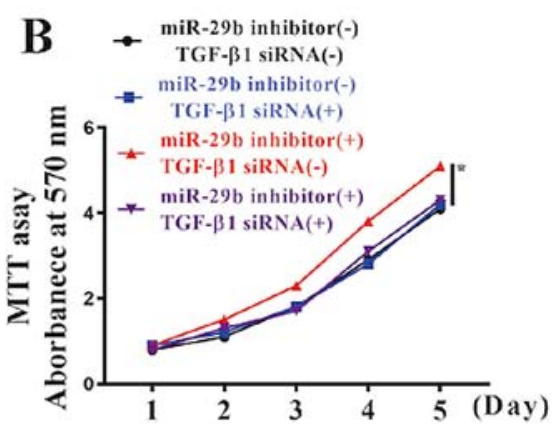

C miR-29binhibitor(-) miR-29b inhibitor(-) miR-29b inhibitor(+) miR-29b inhibitor(+) TGF $\operatorname{TiRNA(-)}$ TGF $\operatorname{TiRNA}(+) \quad$ TGF $\operatorname{siRNA}(-) \quad$ TGF $\operatorname{siRNA}(+)$
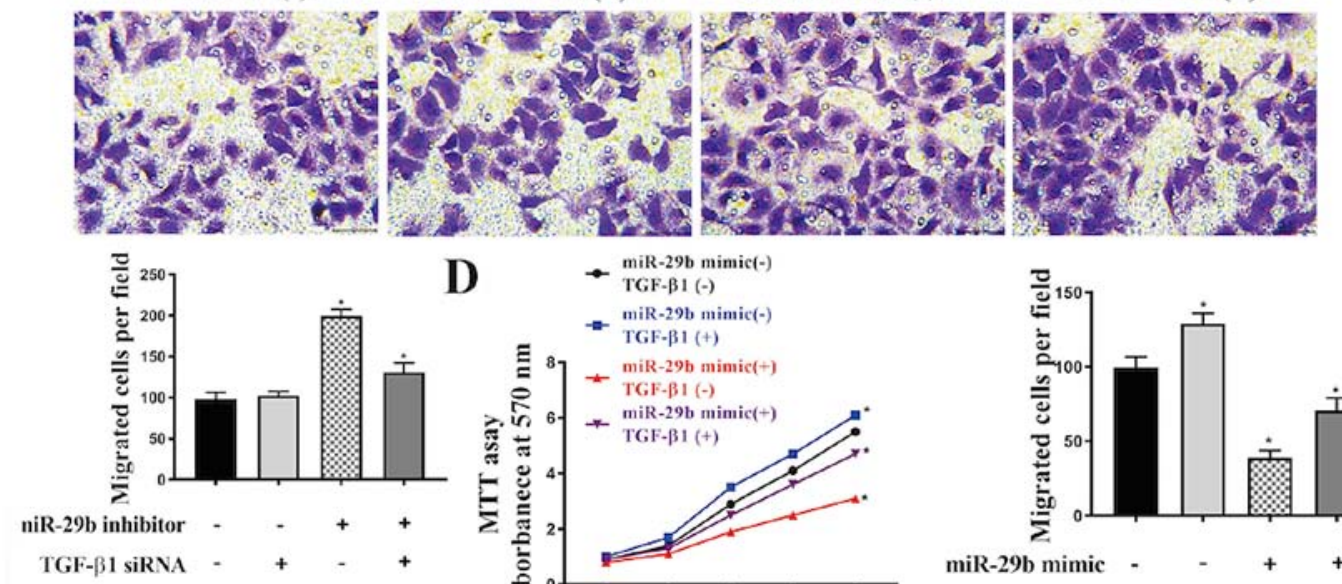

D $\rightarrow \underset{\text { TGF- }-\beta 1(-)}{\operatorname{miR}-29 \mathrm{~b} \text { mimic(-) }}$
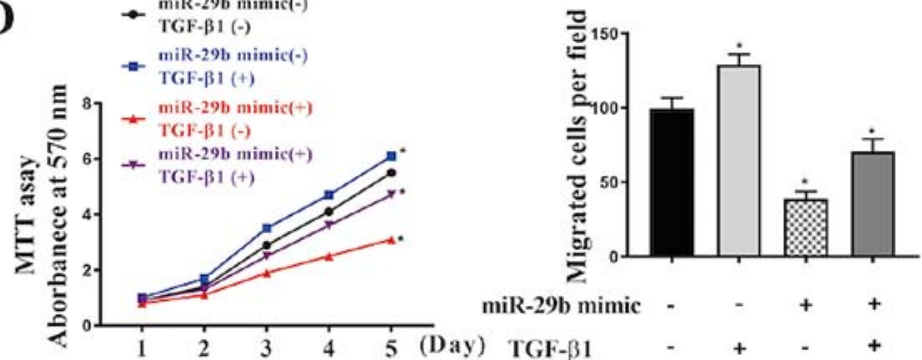

$\mathbf{E}$

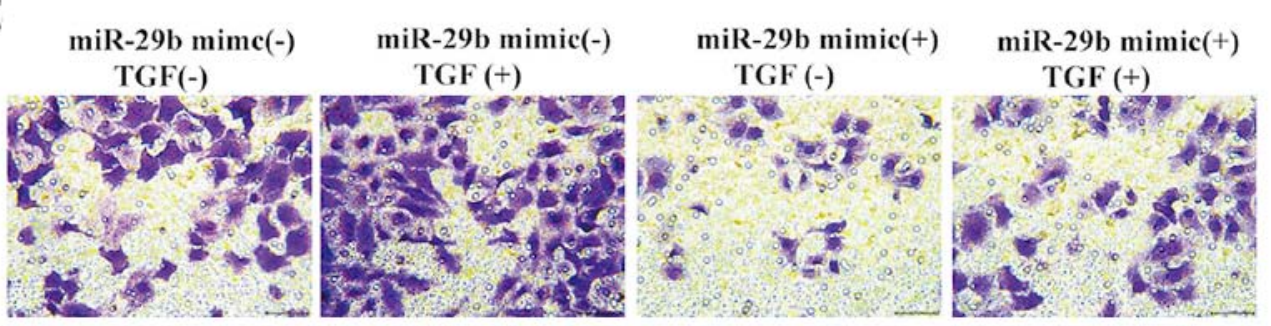

Figure 4. Inhibition of TGF- $\beta 1$ attenuated the cell migration induced by miR-29b inhibition. (A) Expression level of TGF- $\beta 1$ in VSMCs transfected with or without TGF- $\beta 1$ detected by RT-qPCR. (B) MTT assay of VSMCs transfected with miR-29b inhibitor with or without TGF- $\beta 1$ siRNA. (C) Transwell assay of VSMCs transfected with miR-29b inhibitor with or without TGF- $\beta 1$ siRNA. (D) MTT assay of VSMCs transfected with miR-29b mimic with or without TGF- $\beta 1$ treatment. (E) Transwell assay of VSMCs transfected with miR-29b mimic with or without TGF- $\beta 1$ treatment. " $\mathrm{P}<0.05$ vs. control, $\mathrm{n}=6$. Ctrl, control; miR, microRNA; mut, mutant; siRNA, small interfering RNA; NC, negative control; TGF- $\beta 1$, transforming growth factor $\beta 1$; VSMCs, vascular smooth muscle cells; WT, wild-type.

pression of miR-29b significantly suppressed the expression of TGF- $\beta 1$ and decreased the phosphorylation of Smad3, whereas inhibition of miR-29b significantly increased TGF- $\beta 1$ expression and Smad3 phosphorylation compared with the controls (Fig. 2; P<0.05). These effects were observed in HUASMCs (Fig. 2A) and VSMCs (Fig. 2B). This suggests that miR-29b functions by inhibiting the TGF- $\beta / \mathrm{Smad} 3$ pathway.

miR-29b may inhibit the TGF- $\beta /$ Smad3 signaling pathway by directly targeting the TGF- $\beta 1$ gene. TargetScan analysis found that miR-29b had a sequence complementary to the 3'UTR of TGF- $\beta 1$ mRNA. To investigate whether TGF- $\beta 1$ is the direct target of miR-29b, a Dual-luciferase assay was performed using the putative binding site of miR-29b in the 3 '-UTR of TGF- $\beta 1$ as presented in Fig. 3A. The results indicated that luciferase activity was significantly lower for the WT 3'-UTR of TGF- $\beta 1$ compared with the EV control (Fig. $3 \mathrm{~B} ; \mathrm{P}<0.05$ ), whereas the mutant version showed no change in luciferase response. This provides evidence that miR-29b targets TGF- $\beta 1$ by directly binding to its 3'-UTR.

Knockdown of TGF- $\beta 1$ reverses miR-29b inhibition-induced increases in cell viability and migration. To further examine the role of the TGF- $\beta / \mathrm{Smad} 3$ pathway in the miR-29b-induced reduction of cell viability, miR-19b inhibitor was transfected into VSMCs with or without TGF- $\beta 1$ siRNA. Reduction of the expression level of TGF- $\beta 1$ following transfection with TGF- $\beta 1$ siRNA was confirmed by RT-qPCR (Fig. 4A). As shown in Fig. 4B and C, TGF- $\beta 1$ siRNA significantly suppressed miR-29b inhibitor-induced increases in cell viability and 
migration. Furthermore, miR-29b mimic was transfected into VSMCs with or without TGF- $\beta 1$ treatment (Fig. 4D). The MTT and migration assay results in Fig. 4D and E show that miR-29b mimic significantly suppressed cell viability and migration, and the TGF- $\beta 1$ treatment significantly reversed this effect.

\section{Discussion}

The role of miR-29b has been investigated extensively in the past decade, due to the fact that its expression is known to be altered in many cancer and diseased cells compared with normal cells $(16,19,22,23)$. These studies suggest that its major effects include the suppression of cell proliferation and migration, which serve an important role in cancer-associated studies. The present study sought to identify potential targets for miR-29b using TargetScan. TGF- $\beta 1$ was identified as one of the targets of miR-29b, and is known to induce VSMC proliferation and synthesis of extracellular matrix through the Smad 3 signaling pathway (24). TGF- $\beta 1$ is activated by binding to transmembrane kinase receptors, which phosphorylate Smad3 for downstream signaling $(25,26)$. One possible signaling pathway of Smad3 is the upregulation of monocyte chemoattractant protein-1, which is known to serve an important role in angiogenesis and tumor progression by stimulating VSMC migration, and is overexpressed in tumor cells $(27,28)$. In addition, miR-29b has been identified to have a protective role in cardiac fibrosis, whereby thickening of heart valves occurs due to the proliferation of vascular muscle cells, by targeting the TGF- $\beta /$ Smad 3 signaling pathway $(16,29,30)$. The present study investigated the involvement of miR-29b in the TGF- $\beta /$ Smad3 signaling pathway in VSMCs and HUASMCs, as well as the underlying mechanism.

Results from migration assays in the present study clearly demonstrated that the overexpression of miR-29b suppressed the viability and migration of VSMCs and HUASMCs, while suppression of its expression exhibited the reverse effect. This is consistent with the previous finding that miR-29b is significantly downregulated in the VSMCs of patients with IA (19). Furthermore, the present study demonstrated that miR-29b overexpression reduces the expression of TGF- $\beta 1$ and phosphorylation of Smad3, while miR-29b downregulation has the opposite effect in VSMCs and HUASMCs. The luciferase assay suggested that miR-29b targets the 3'-UTR of TGF- $\beta 1$, which in turn reduces the expression of TGF- $\beta 1$ and suppresses the TGF- $\beta /$ Smad 3 signaling pathway, thus reducing cell viability and migration. For further validation, changes in cell migration were monitored while the expression of TGF- $\beta 1$ was manipulated. This was achieved by either providing a TGF- $\beta 1$ treatment to increase its level, or transfecting with an siRNA that interferes with the translation of TGF- $\beta 1$. For the cells with increased viability due to miR-29b inhibition and hence overexpressed TGF- $\beta$, the TGF- $\beta 1$ siRNA partially reversed the effect. Furthermore, with miR-29b mimic, where miR-29b was upregulated, TGF- $\beta$ expression was reduced and viability was reduced, the addition of TGF- $\beta 1$ treatment increased proliferation. These findings are consistent with the proposed mechanism.

Overall, the results indicated the potential role of miR-29b in IA. Inhibition of miR-29b in the VSMCs is responsible for the overexpression of TGF- $\beta$, which may promote cell proliferation and migration via the TGF- $\beta / S \operatorname{mad} 3$ signaling pathway. Increased rates of cell proliferation and migration are important aspects in the switch to the synthetic phenotype (31). In response to a changing environment, such as vascular injury, this phenotype would promote cell growth and the synthesis of extracellular matrix, which helps in vascular repair. Unfortunately, this property is also the main contributor in the progression of IA $(32,33)$. The present study has shown that these effects can be suppressed in vitro by transfecting cells with miR-29b mimic to upregulate miR-29b, or by the suppression of TGF- $\beta 1$ by transfecting cells with siRNA to interfere with its translation. These results provide a possible approach for a less-invasive treatment for patients with IA. However, further investigation of the expression of miR-29b in VSMCs from patients with IA is required in order to explore the upstream gene regulation for miR-29b.

\section{Acknowledgements}

Not applicable.

\section{Funding}

No funding was received.

\section{Availability of data and materials}

All data generated or analyzed during this study are included in this published article.

\section{Authors' contributions}

LL designed the study and wrote the manuscript. LL, SR and $\mathrm{XH}$ performed the experiments. $\mathrm{ZZ}, \mathrm{LJ}$ and $\mathrm{HJ}$ collected and analyzed data. All authors have read and approved the manuscript.

\section{Ethics approval and consent to participate}

Not applicable.

\section{Patient consent for publication}

Not applicable.

\section{Competing interests}

The authors declare they have no competing interests.

\section{References}

1. Frösen J, Tulamo R, Paetau A, Laaksamo E, Korja M, Laakso A, Niemelä $\mathrm{M}$ and Hernesniemi J: Saccular intracranial aneurysm: Pathology and mechanisms. Acta Neuropathol 123: 773-786, 2012.

2. Bor AS, Rinkel GJ, Adami J, Koffijberg H, Ekbom A, Buskens E, Blomqvist P and Granath F: Risk of subarachnoid haemorrhage according to number of affected relatives: A population based case-control study. Brain 131: 2662-2665, 2008.

3. Louw DF, Asfora WT and Sutherland GR: A brief history of aneurysm clips. Neurosurg Focus 11: E4, 2001. 
4. Ailawadi G, Moehle CW, Pei H, Walton SP, Yang Z, Kron IL, Lau CL and Owens GK: Smooth muscle phenotypic modulation is an early event in aortic aneurysms. J Thorac Cardiovasc Surg 138: 1392-1399, 2009

5. Nakajima N, Nagahiro S, Sano T, Satomi J and Satoh K: Phenotypic modulation of smooth muscle cells in human cerebral aneurysmal walls. Acta Neuropathol 100: 475-480, 2000.

6. Ali MS, Starke RM, Jabbour PM, Tjoumakaris SI, Gonzalez LF, Rosenwasser RH, Owens GK, Koch WJ, Greig NH and Dumont AS: TNF- $\alpha$ induces phenotypic modulation in cerebral vascular smooth muscle cells: Implications for cerebral aneurysm pathology. J Cereb Blood Flow Metab 33: 1564-1573, 2013.

7. Kawai-Kowase K and Owens GK: Multiple repressor pathways contribute to phenotypic switching of vascular smooth muscle cells. Am J Physiol Cell Physiol 292: C59-C69, 2007.

8. Owens GK, Kumar MS and Wamhoff BR: Molecular regulation of vascular smooth muscle cell differentiation in development and disease. Physiol Rev 84: 767-801, 2004.

9. Lacolley P, Regnault V, Segers P and Laurent S: Vascular smooth muscle cells and arterial stiffening: Relevance in development, aging, and disease. Physiol Rev 97: 1555-1617, 2017.

10. Mao N, Gu T, Shi E, Zhang G, Yu L and Wang C: Phenotypic switching of vascular smooth muscle cells in animal model of rat thoracic aortic aneurysm. Interact Cardiovasc Thorac Surg 21: 62-70, 2015.

11. van Rooij E, Marshall WS and Olson EN: Toward microRNAbased therapeutics for heart disease: The sense in antisense. Circ Res 103: 919-928, 2008.

12. Small EM and Olson EN: Pervasive roles of microRNAs in cardiovascular biology. Nature 469: 336-342, 2011.

13. van Rooij E and Olson EN: MicroRNA therapeutics for cardiovascular disease: Opportunities and obstacles. Nat Rev Drug Discov 11: 860-872, 2012.

14. Liu D, Han L, Wu X, Yang X, Zhang Q and Jiang F: Genome-wide microRNA changes in human intracranial aneurysms. BMC Neurol 14: 188, 2014

15. Yan B, Guo Q, Fu FJ, Wang Z, Yin Z, Wei YB and Yang JR: The role of miR-29b in cancer: Regulation, function, and signaling. Onco Targets Ther 8: 539-548, 2015.

16. Zhang Y, Huang XR, Wei LH, Chung AC, Yu CM and Lan HY: miR-29b as a therapeutic agent for angiotensin II-induced cardiac fibrosis by targeting TGF- $\beta /$ Smad 3 signaling. Mol Ther 22: 974-985, 2014

17. McMullen JR and Bernardo BC: Inhibition of miR-29 protects against cardiac hypertrophy and fibrosis: New insight for the role of miR-29 in the heart. Non-coding RNA Investig 2: 14, 2018.

18. Wang G, Matsuura I, He D and Liu F: Transforming growth factor-\{beta\}-inducible phosphorylation of Smad3. J Biol Chem 284: 9663-9673, 2009.

19. Sun L, Zhao M, Zhang J, Lv M, Li Y, Yang X, Liu A and Wu Z: MirR-29B downregulation induces phenotypic modulation of vascular smooth muscle cells: Implication for intracranial aneurysm formation and progression to rupture. Cell Physiol Biochem 41: 510-518, 2017.

20. Fang $\mathrm{J}$, Xu H, Yang $\mathrm{C}$, Morsalin S, Kayarthodi S, Rungsrisuriyachai K, Gunnal U, Mckenzie B, Rao VN and Reddy ES: Ets related gene and Smad3 proteins collaborate to activate transforming growth factor-beta mediated signaling pathway in ETS related gene-positive prostate cancer cells. J Pharm Sci Pharmacol 1: 175-181, 2014.
21. Livak KJ and Schmittgen TD: Analysis of relative gene expression data using real-time quantitative PCR and the 2(-Delta Delta C(T)) Method. Methods 25: 402-408, 2001.

22. Kole AJ, Swahari V, Hammond SM and Deshmukh M: miR-29b is activated during neuronal maturation and targets BH3-only genes to restrict apoptosis. Genes Dev 25: 125-130, 2011.

23. Eyholzer M, Schmid S, Wilkens L, Mueller BU and Pabst T: The tumour-suppressive miR-29a/b1 cluster is regulated by CEBPA and blocked in human AML. Br J Cancer 103: 275-284, 2010.

24. Tsai S, Hollenbeck ST, Ryer EJ, Edlin R, Yamanouchi D, Kundi R, Wang C, Liu B and Kent KC: TGF-beta through Smad3 signaling stimulates vascular smooth muscle cell proliferation and neointimal formation. Am J Physiol Heart Circ Physiol 297: H540-H549, 2009.

25. Flanders KC, Sullivan CD, Fujii M, Sowers A, Anzano MA, Arabshahi A, Major C, Deng C, Russo A, Mitchell JB, et al: Mice lacking Smad 3 are protected against cutaneous injury induced by ionizing radiation. Am J Pathol 160: 1057-1068, 2002.

26. Shi Y and Massagué J: Mechanisms of TGF-beta signaling from cell membrane to the nucleus. Cell 113: 685-700, 2003.

27. Ma J, Wang Q, Fei T, Han JD and Chen YG: MCP-1 mediates TGF-beta-induced angiogenesis by stimulating vascular smooth muscle cell migration. Blood 109: 987-994, 2007.

28. Salcedo R, Ponce ML, Young HA, Wasserman K, Ward JM, Kleinman HK, Oppenheim JJ and Murphy WJ: Human endothelial cells express CCR 2 and respond to MCP-1: Direct role of MCP-1 in angiogenesis and tumor progression. Blood 96: 34-40, 2000.

29. Ma F, Li Y, Jia L, Han Y, Cheng J, Li H, Qi Y and Du J: Macrophage-stimulated cardiac fibroblast production of IL-6 is essential for TGF $\beta / S m a d$ activation and cardiac fibrosis induced by angiotensin II. PLoS One 7: e35144, 2012.

30. van Rooij E, Sutherland LB, Thatcher JE, DiMaio JM, Naseem RH, Marshall WS, Hill JA and Olson EN: Dysregulation of microRNAs after myocardial infarction reveals a role of miR-29 in cardiac fibrosis. Proc Natl Acad Sci USA 105: 13027-13032, 2008.

31. Davis-Dusenbery BN, Wu C and Hata A: Micromanaging vascular smooth muscle cell differentiation and phenotypic modulation. Arterioscler Thromb Vasc Biol 31: 2370-2377, 2011.

32. ten Dijke P and Arthur HM: Extracellular control of TGFbeta signalling in vascular development and disease. Nat Rev Mol Cell Biol 8: 857-869, 2007.

33. Petsophonsakul P, Furmanik M, Forsythe R, Dweck M, Schurink GW, Natour E, Reutelingsperger C, Jacobs M, Mees B and Schurgers L: Role of vascular smooth muscle cell phenotypic switching and calcification in aortic aneurysm formation. Arterioscler Thromb Vasc Biol 39: 1351-1368, 2019.

(i) $(-)$ This work is licensed under a Creative Commons Attribution-NonCommercial-NoDerivatives 4.0 International (CC BY-NC-ND 4.0) License. 